\title{
THE INVESTIGATION OF BACTERIAL ADHESION OF PALATINE TONSILS EPITHELIAL CELLS IN PATIENT WITH INFECTIOUS MONONUCLEOSIS
}

\author{
Aleksandr Nadraga \\ Department of pediatric infectious diseases ${ }^{I}$ \\ nadraga09@gmail.com \\ Aleksandr Lutsyk \\ Department of Histology, Cytology and Embryology ${ }^{1}$ \\ lutsykalexander@gmail.com \\ Khrystyna Klymenko \\ Department of pediatric infectious diseases ${ }^{1}$ \\ kristinkalnmu@gmail.com \\ Olena Khomyn \\ Department of pediatric infectious diseases ${ }^{1}$ \\ khomyn.olena@gmail.com \\ ${ }^{1}$ Danylo Halytsky Lviv National Medical University \\ 69 Pekarska str., Lviv, Ukraine, 79010
}

\begin{abstract}
Aim. To evaluate the features of pharynx tonsils mucous membrane colonization by pathogenic and opportunistic microorganisms by using the pharynx palatine tonsils epithelium electron microscopic examination of the patients with infectious mononucleosis and acute streptococcal tonsillitis.

Materials and methods. Two patients - patient P., 12 years old with a confirmed diagnosis of infectious mononucleosis and patient A., 8 years old with confirmed acute streptococcal tonsillitis. The patients were taken a bacteriological examination of the mucus and epithelium scraping from the surface of the pharyngeal tonsils. Tissue samples were examined in the electron microscopy laboratory of the Lviv National University.

Results and discussion. 36 tonsils epithelial tissue micro preparations of patient A. and 41 micro preparations of patient $\mathrm{P}$. were studied. Streptococcus pyogenes, Str. pneumoniae, Str. viridans, Candida albicans, as well as non-pathogenic bacteria: Diphtheroides sp., Neisseria sp., Corynebacterium spp. were identified as result of the patient P. bacteriological examination of mucus from the surface of the pharyngeal tonsils. Staph. aureus, Str. viridans, Str. pneumoniae were identified during a bacteriological examination of patient A. Eosinophils with a two-segmented nucleus, specific granularity, phagocytosed spherical bacteria in the cytoplasm were detected during the histological examination of the materials taken from the surface of the patient's tonsils with acute tonsillitis. Research showed that bacteria were accumulated not only in the structure of extracellular detritus. Numerous bacteria accumulations were also found in the cytoplasm of the epithelial cells in the patient with infectious mononucleosis. The cell's shape looked like a bunch of grapes.

Conclusions. The electron microscopic examination showed differences in the coccal flora localization: the extracellular localization of bacteria in the patient with acute bacterial tonsillitis and intraepithelial presence of the bacteria in the patient with tonsillitis during infectious mononucleosis were found.
\end{abstract}

Keywords: Infectious mononucleosis, children, bacterial tonsillitis, Epstein-Barr virus, bacterial adhesion.

DOI: $10.21303 / 2504-5679.2021 .001835$

\section{Introduction}

One of the most common symptoms of infectious mononucleosis (MI), which is caused by Epstein-Barr virus (EBV), is tonsillitis in which the pathological process involves the palatine tonsils, which are covered with a dense, membrane-like exudate [1]. The exudate contains bacteria, bacterial residues and tissue detritus. According to the literature, most of the microorganisms found in bacteriological studies of mucus from the tonsils of the pharynx in MI belong to the 
microflora, which in healthy individuals inhabits the surface of the tonsils. At the same time, betahemolytic streptococci, mainly groups A, C, G, as well as representatives of anaerobic microflora - Fusobacterium nucleatum, Prevotella intermedia are detected [2].

According to Stenfors et. al. [3] in infectious mononucleosis on the surface of one epithelial cell located on the surface of the palatine tonsil can be fixed more than 500 different bacteria $[4,5]$. Studies have shown that the adhesion of bacteria to the epitheliocytes of the tonsils, as well as the epithelium of the nasopharynx is inversely proportional to the age of patients; at the same time, the intensity of this process increases in accordance with the increase in the duration of the disease [6]. Persistence of EBV can activate the penetration of certain bacterial pathogens into the epithelial tissues of the tonsils [7].

The aim of the study was to determine the peculiarities of colonization of the mucous membrane of the tonsils by pathogenic and opportunistic microorganisms in patients with MI caused by EBV and acute streptococcal tonsillitis.

\section{Materials and methods}

The study was conducted on the basis of the Infectious Diseases Communal Clinical Hospital in 2020. Two patients were under observation: a 12-year-old boy, P., who was in hospital with a diagnosis of MI, and an 8-year-old boy, A., who was diagnosed and treated for acute streptococcal tonsillitis.

The research methods used in the study are scientifically substantiated, comply with the principles of the Helsinki Declaration of Human Rights (1950), the Council of Europe Convention on Human Rights and Biomedicine (1997) and the requirements of current legislation of Ukraine. In the course of the research work, the rights and interests of the research participants were observed in accordance with the generally accepted norms of morality, ethics and deontology. Patients were admitted to the study with the written informed consent of their parents. The protocol of the Ethics Commission of the Danylo Halytsky Lviv National Medical University №3 dated 14.12.2016.

The diagnosis of infectious mononucleosis in patient P. was determined on the basis of typical symptoms of the disease, characteristic changes in the general blood test (in particular, the presence of atypical mononuclear cells in the blood smear) and elevated levels of specific immunoglobulins (IgM to capsid antigen). Bacteriological examination of mucus from the surface of the tonsils of the pharynx in this patient revealed: Streptococcus pyogenes at a concentration of $4.0 \mathrm{lgCFU}$, Str. pneumoniae $3.7 \mathrm{lgCFU}$, Str. viridans - 3.1 lgCFU, Candida albicans - $2.7 \mathrm{lgCFU}$, and also nonpathogenic bacteria: Diphtheroides sp., Neisseria sp., Corynebacterium spp.

Acute streptococcal tonsillitis in child A. was diagnosed by the characteristic symptoms of the disease, the presence of signs of inflammation in the general blood test (leukocytosis, accelerated ESR), high levels of C-reactive protein and the results of bacteriological examination of mucus from the tonsils (Staph. aureus at the concentration of $8.0 \operatorname{lgCFU}$, Str.viridans $-6.1 \operatorname{lgCFU}$, Str.pneumonia - $2.5 \operatorname{lgCFU})$.

On the first day of the treatment in the hospital, patients were scraped from the surface of the tonsils epithelium of the pharynx. Tissue samples were examined in the electron microscopy laboratory of the Interfaculty Laboratory of Experimental Research Methods of Ivan Franko National University of Lviv. The material was fixed with a $1.5 \%$ solution of OsO4 (CHEM, USA) in $0.2 \mathrm{M}$ sodium cacodylate (Fluka) at $\mathrm{pH} 7.2$ for 2-2.5 hours and dehydrated in increasing concentrations of ethyl alcohol $(50 \%, 70 \%, 90 \%, 98 \%)$ for 30 minutes per each concentration. After carrying out through propylene oxide for $10 \mathrm{~min}$, the samples were poured into epoxy resin Epon-812 (Fluka) followed by polymerization for $24 \mathrm{~h}$ in a thermostat at a temperature of $60^{\circ} \mathrm{C}$. Sections were prepared on an ultramicrotome UMTP-6M using a diamond knife DIATOM. Contrast was performed in $1 \%$ uranyl acetate solution and in Reynolds contrast medium $[8,9]$. The sections were examined using a TEM-100 transmission electron microscope (Ukraine) and photographed with a SONY-H9 digital camera (Japan).

\section{Results of the research}

A total of 36 preparations of the epithelial tissue of the patient A. tonsils and 41 preparations of patient P. tonsils were studied. It was found that most of the surface of the tonsils was covered with a stratified squamous non-keratinized epithelium, which in some areas was subject 
to keratinization. Neighboring epitheliocytes formed numerous desmosomal contacts and plasma membrane interdigitations. The nuclei of oval cells were with single invaginations of the nuclear envelope. Freely scattered ribosomes, as well as individual mitochondria and elements of the granular endoplasmic reticulum were found in the cytoplasm. Numerous tonofibrils formed a characteristic intracellular network. Under conditions of acute streptococcal tonsillitis in detritus, which covered the surface of the epithelium of the tonsil, an accumulation of bacteria was found, which in shape and location could be regarded as cocci; at the same time, pathological inclusions and bacteria were not visualized in the cytoplasm of epitheliocytes (Fig. 1-3).

In the studied material obtained from patient P., eosinophils with a characteristic two-segment nucleus, a specific elliptical granularity, and, presumably, phagocytosed spherical bacteria in the cytoplasm were observed in some preparations near the surface of the tonsils (Fig. 4).

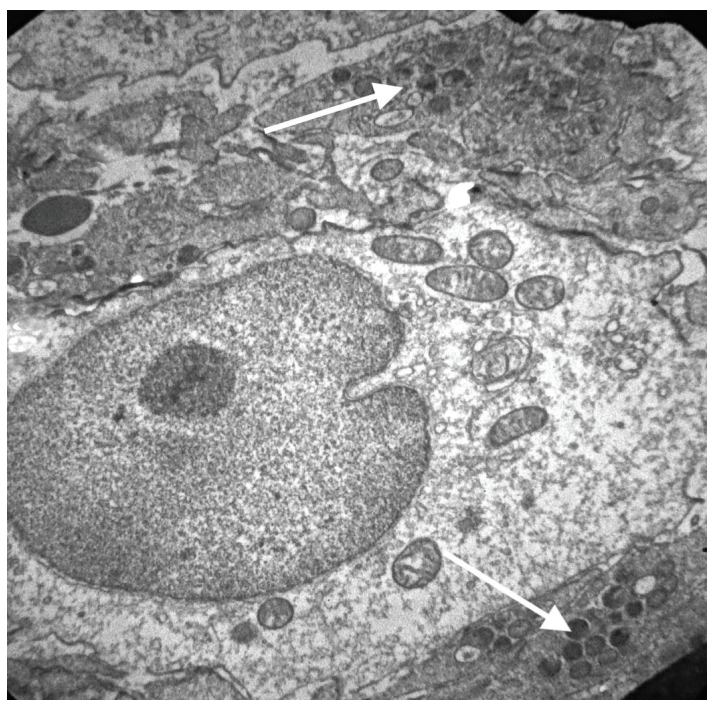

Fig. 1. Electron micrograph of the epitheliocyte of the tonsil of a patient with acute bacterial tonsillitis. Arrows indicate clusters of electron-dense bacteria that are localized in the extracellular space filled with mucus and tissue detritus. Magnification $\times 6000$

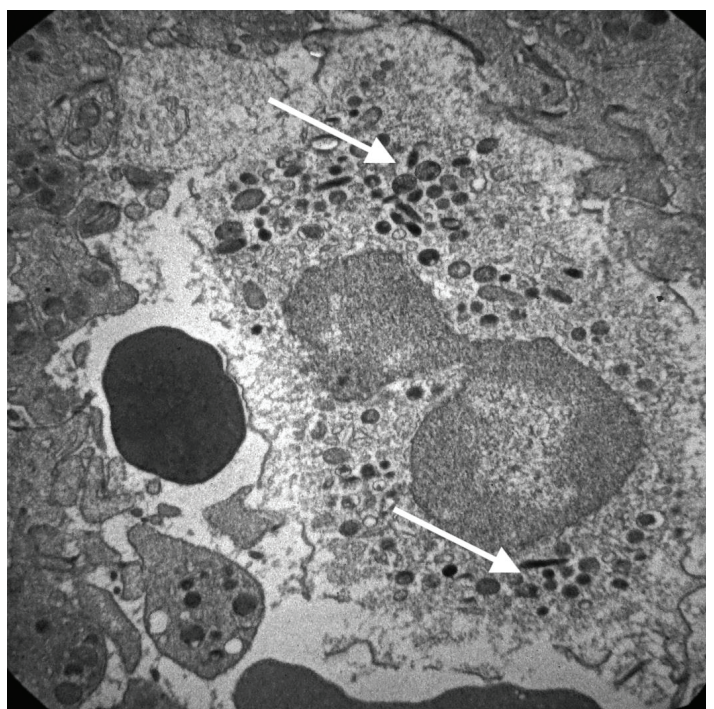

Fig. 2. Electron micrograph of scraping the surface of the palatine tonsil of a patient with acute bacterial tonsillitis. The plasma membrane of the epitheliocyte is in a state of complete destruction, the cytoplasm is filled with clusters of electron-dense bacteria (indicated by arrows).

Magnification $\times 6000$ 


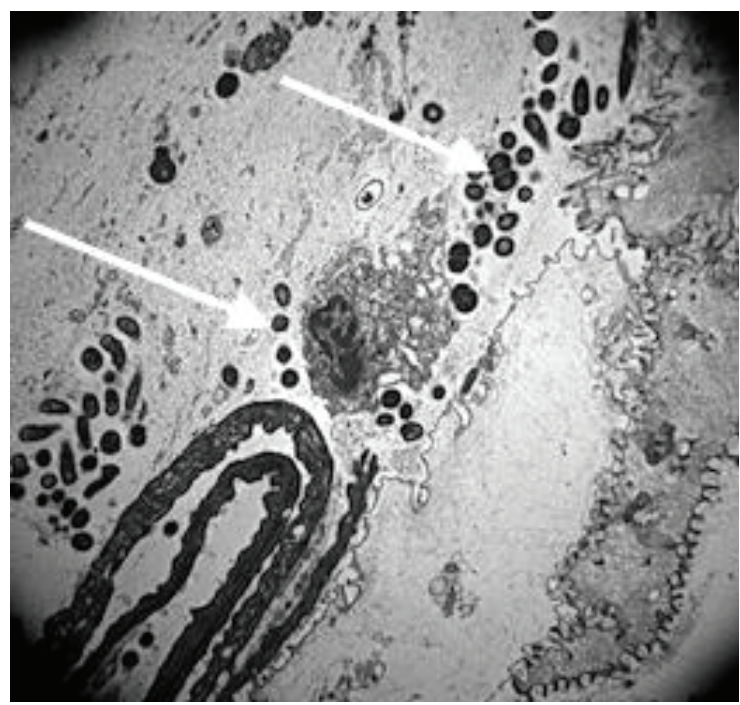

Fig. 3. Electron micrograph of the crypt of the tonsil of a patient with acute bacterial tonsillitis. Clusters of electron-dense spherical and ovoid bacteria (marked with arrows) are visualized in the mucus-filled extracellular space.

Magnification $\times 10000$

In the cytoplasm of cells of the superficial epithelium of the tonsil, the vesicular system, large mitochondria, multiple fibrils and intracellular inclusions are well developed, the folds of the cell membrane are clearly visible [10]. In addition to the accumulation of bacteria in extracellular detritus, accumulations of numerous bacteria were found in the cytoplasm of epitheliocytes; some of them had the appearance of grapes (Fig. 4-7).

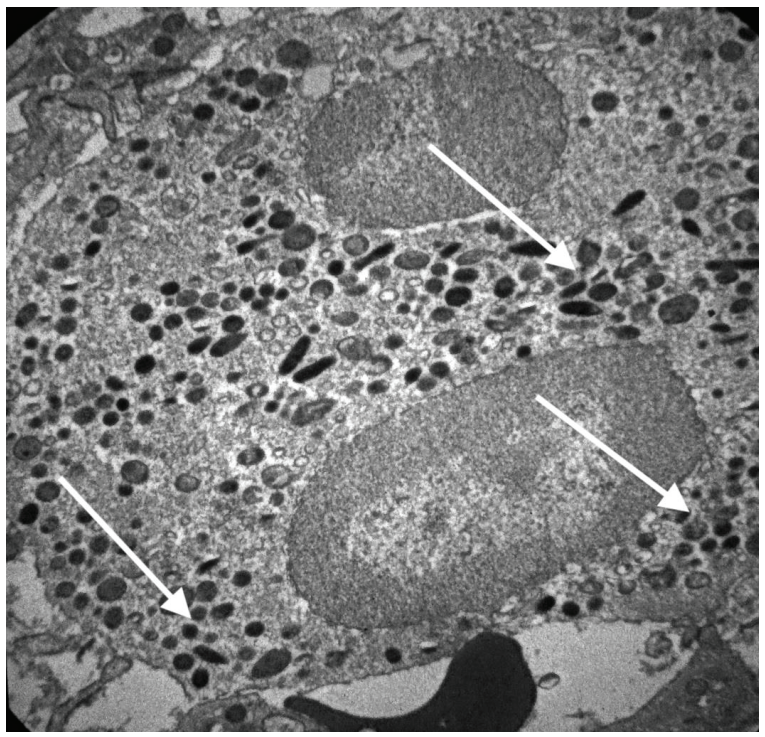

Fig. 4. Electron micrograph of an eosinophil in the palatine tonsil of a patient with infectious mononucleosis. Part of the electron-dense cytoplasmic granules is represented by phagocytosed spherical bacteria (marked with arrows). Magnification $\times 6000$

Electron microscopy revealed differences in the localization of coccal flora (which morphologically can be classified as streptococci) in epithelial tissues in tonsillitis of various etiologies extracellular localization of bacteria in acute bacterial tonsillitis and intraepithelial in tonsillitis on the background of MI. 


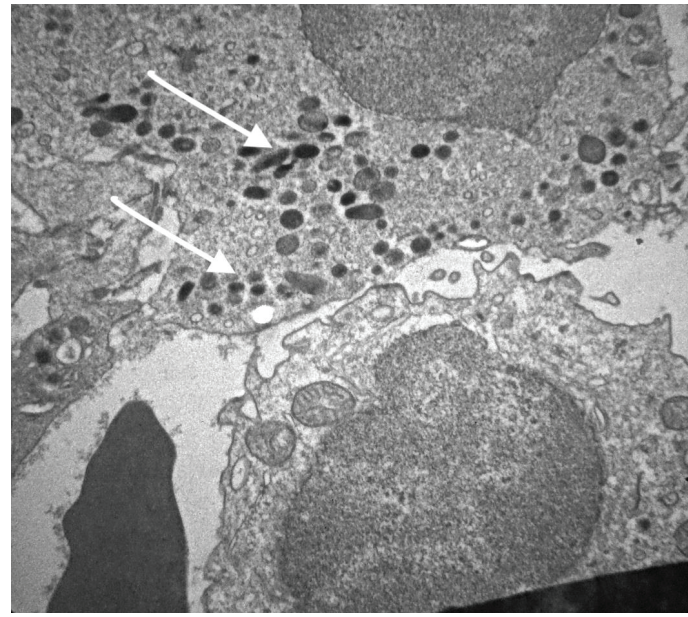

Fig. 5. Electron micrograph of epitheliocytes of the palatine tonsil surface of a patient with infectious mononucleosis. Multiple colonies of bacteria in the cytoplasm of the cell are marked with arrows, the cell free of bacteria is next to them. Magnification $\times 6000$

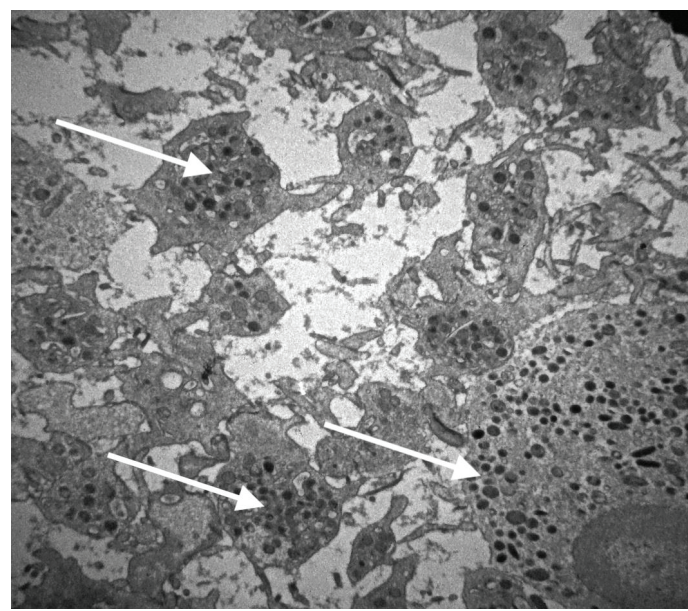

Fig. 6. Electron micrograph of scraping the palatine tonsil of a patient with infectious mononucleosis. Multiple colonies of bacteria in the cytoplasm of the epitheliocyte and in the mass of tissue detritus, which fills the intercellular space. Magnification $\times 6000$

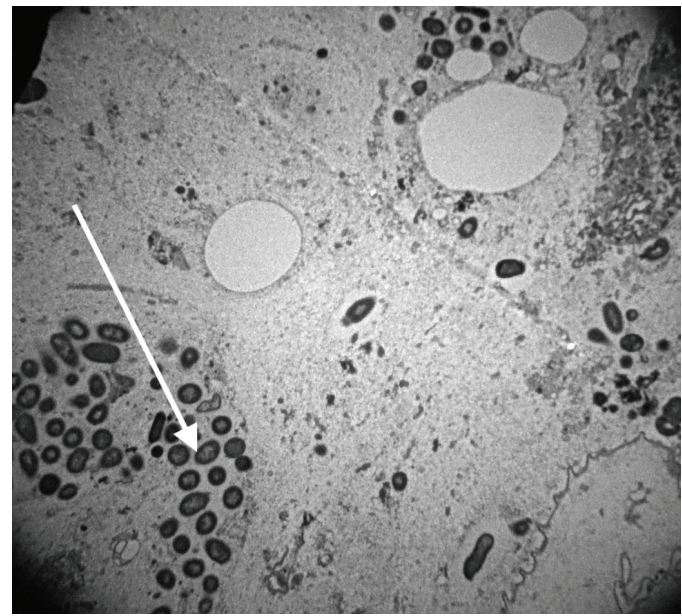

Fig. 7. Electron micrograph of a fragment of an epitheliocyte of the surface of the palatine tonsil of a patient with infectious mononucleosis. Numerous bacteria in the cytoplasm of the cell are marked with the arrow. Magnification $\times 10000$ 


\section{Discussion of research results}

The mucous membrane of the nasopharynx and oropharynx, and tonsils in particular, has several rather complex mechanisms of protection against colonization and invasion of microorganisms. On the first line of defense, pathogenic microorganisms can be adsorbed and neutralized by a film of mucus that covers the surface of the tonsils and contains bactericidal substances such as digestive enzymes, lysozyme, lactoferrin, defensins, etc. [11, 12]. Protective mechanisms include epithelial desquamation, nonspecific (peroxidase, interferons, lysozyme, complement) and specific (immunoglobulins) factors, as well as mucociliary clearance and phagocytosis. All of the above causes significant resistance of the mucous membrane of the nasopharynx and oropharynx to bacterial invasion $[8,13,14]$.

It can be assumed that EBV affecting B-lymphocytes leads to a decrease in their production of immunoglobulins. Two types of immunoglobulins play an important role in the pathogenesis of tonsillitis. They are: a secretory immunoglobulin A (sIgA), which prevents bacteria from settling on the epithelial surface, and IgG, which induces bacteriolysis and enhances phagocytosis upon contact with bacteria. The surface of the palatine tonsils is covered with a stratified squamous non-keratinized epithelium, in which there are no ciliated cells, which makes it impossible to use the mechanism of mucociliary clearance, which plays an important role in sanogenesis of the airways [9, 15].

Traditionally, streptococci have been classified as extracellular pathogens, but in recent decades, a number of experimental studies have found that some streptococci, including Str. pyogenes, can be localized intracellularly (this may explain the presence of streptococci in the oral cavity after antibiotic therapy) [10]. Intracellular invasion of streptococci was first described in 1994 by LaPenta et. al. who, using the cell culture infection model, demonstrated that Str. pyogenes can infect human epithelial cells that do not have the ability to phagocytose, with the same frequency as classical intracellular pathogens such as listeria, chlamydia or salmonella [16-18].

Inflammatory changes in the mucous membrane of the oropharynx are also caused by increased production of inflammatory mediators, stimulation of sensitive nerve endings, dilation of blood vessels and increase their permeability, infiltration of immune response cells such as macrophages, mast cells, lymphocytes, polymorphonuclear leukocytes. In the development of these processes, of course, the leading role is played by the activation of opportunistic bacterial microflora, which always densely inhabits the mucous membranes of the oropharynx, against the background of immunodeficiency caused by herpesvirus infection [19].

Several mechanisms of streptococcal invasion into epithelial and endothelial cells have been studied. SfbI and M proteins initiate this process by the fibronectin binding, which further interacts with integrin receptors on the cell surface. Clustering of integrin receptors causes aggregation of the caveolae, resulting in large invaginations of the plasma membrane, which are then colonized by streptococci [20]. Some streptococci, using M-protein-bound fibronectin, induce focal adhesion complexes and penetrate the cell membrane by one of two mechanisms - zipper-like mechanism or membrane ruffling [21]. The first mechanism directs streptococci to a safer cavernous-somatic compartment of the cell, and the second directs bacteria to phagolysosomes, where most of them are destroyed.

It can be assumed that the high degree of bacteria adhesion to epithelial surfaces serves as a basis for massive bacterial colonization, which is observed in EBV tonsillitis with the formation of membranous layers [22-24]. In addition to the massive adhesion of bacteria, mainly cocci, on the cells of the superficial epithelium of the tonsils of the pharynx, the phenomenon of bacterial invasion of epitheliocytes in acute EBV infection is still insufficiently studied. The results of the study indicate that EBV and $\beta$-hemolytic streptococcus play a synergistic role in the development of inflammatory diseases of the upper respiratory tract.

Study limitations. There were several limitations in the study. First, biofilms with differentiated bacteria were not studied. This research was limited by the results of conventional bacteriological studies. Second, the number of patients included in the study has to be increased to achieve significant differences in the data studied.

Prospect for further research. Further studies are needed to determine whether the identified features of bacterial colonization of the tonsils are a justification for the appointment of adequate antibiotic therapy. 


\section{Conclusion}

Electron microscopic studies revealed differences in the localization of coccal flora (which morphologically can be classified as streptococci) in epithelial tissues in tonsillitis of various etiologies. The extracellular localization of bacteria in acute bacterial tonsillitis and intraepithelial in tonsillitis on the background of EBV and streptococci in upper respiratory tract lesions in children with MI.

\section{Conflict of interests}

The authors declare that they have no conflicts of interest.

\section{References}

[1] Boiarska, L. M., Hrebeniuk, L. V., Ivanova, K. O., Akhtyrsky, V. V. (2019). Condition of nasopharynx contamination in children with chronic tonsillitis and gastroesophageal reflux disease. Zaporozhye Medical Journal, 21 (5), 650-655. doi: http:/ doi.org/10.14739/2310-1210.2019.5.179441

[2] Lee, J., Chang, D.-Y., Kim, S.-W., Choi, Y. S., Jeon, S.-Y., Racanelli, V. et. al. (2015). Age-related differences in human palatine tonsillar B cell subsets and immunoglobulin isotypes. Clinical and Experimental Medicine, 16 (1), 81-87. doi: http:// doi.org/10.1007/s10238-015-0338-5

[3] Räisänen, S., Myklebust, R., Bye, H.-M., Stenfors, L.-E. (2000). Bacterial penetration into tonsillar surface epithelium during infectious mononucleosis. The Journal of Laryngology \& Otology, 114(11), 848-852. doi: http://doi.org/10.1258/0022215001904149

[4] Rieth, K. K. S., Gill, S. R., Lott-Limbach, A. A., Merkley, M. A., Botero, N., Allen, P. D., Miller, M. C. (2018). Prevalence of High-Risk Human Papillomavirus in Tonsil Tissue in Healthy Adults and Colocalization in Biofilm of Tonsillar Crypts. JAMA Otolaryngology-Head \& Neck Surgery, 144 (3), 231-237. doi: http://doi.org/10.1001/jamaoto.2017.2916

[5] Shelly, A., Gupta, P., Ahuja, R., Srichandan, S., Meena, J., Majumdar, T. (2020). Impact of Microbiota: A Paradigm for Evolving Herd Immunity against Viral Diseases. Viruses, 12 (10), 1150. doi: http://doi.org/10.3390/v12101150

[6] Miller, J. M., Binnicker, M. J., Campbell, S., Carroll, K. C., Chapin, K. C., Gilligan, P. H. et. al. (2018). A Guide to Utilization of the Microbiology Laboratory for Diagnosis of Infectious Diseases: 2018 Update by the Infectious Diseases Society of America and the American Society for Microbiologya. Clinical Infectious Diseases, 67 (6), e1-e94. doi: http://doi.org/10.1093/cid/ciy381

[7] Yaxley, K. L. (2020). Infectious mononucleosis complicated by peritonsillar abscess and postural orthostatic tachycardia syndrome: A case report. SAGE Open Medical Case Reports, 8. doi: http://doi.org/10.1177/2050313x20915413

[8] Daddow, L. Y. (1986). An abbreviated method of the double lead stain technique. J Submicrosc Cytol, 18 (1), $221-224$.

[9] Reynolds, E. S. (1963). The use of lead citrate at high pH as an electron-opaque stain in electron microscopy. Journal of Cell Biology, 17 (1), 208-212. doi: http://doi.org/10.1083/jcb.17.1.208

[10] Urbaniak, C., Lorenzi, H., Thissen, J., Jaing, C., Crucian, B., Sams, C. et. al. (2020). The influence of spaceflight on the astronaut salivary microbiome and the search for a microbiome biomarker for viral reactivation. Microbiome, 8 (1). doi: http:// doi.org/10.1186/s40168-020-00830-z

[11] Wu, S., Hammarstedt-Nordenvall, L., Jangard, M., Cheng, L., Radu, S. A., Angelidou, P. et. al. (2021). Tonsillar Microbiota: a Cross-Sectional Study of Patients with Chronic Tonsillitis or Tonsillar Hypertrophy. mSystems, 6 (2). doi: http:// doi.org/10.1128/msystems.01302-20

[12] Cruz-Muñoz, M. E., Fuentes-Pananá, E. M. (2018). Beta and Gamma Human Herpesviruses: Agonistic and Antagonistic Interactions with the Host Immune System. Frontiers in Microbiology, 8. doi: http://doi.org/10.3389/fmicb.2017.02521

[13] Danstrup, C. S., Klug, T. E. (2019). Low rate of co-infection in complicated infectious mononucleosis. Danish Medical Journal, 66 (9), A5564.

[14] Klug, T. E. (2017). Peritonsillar abscess: clinical aspects of microbiology, risk factors, and the association with parapharyngeal abscess. Danish Medical Journal, 64 (3), B5333.

[15] Feller, L., Altini, M., Khammissa, R. A. G., Chandran, R., Bouckaert, M., Lemmer, J. (2013). Oral mucosal immunity. Oral Surgery, Oral Medicine, Oral Pathology and Oral Radiology, 116 (5), 576-583. doi: http://doi.org/10.1016/j.00oo.2013.07.013

[16] Matrajt, L., Gantt, S., Mayer, B. T., Krantz, E. M., Orem, J., Wald, A. et. al. (2017). Virus and host-specific differences in oral human herpesvirus shedding kinetics among Ugandan women and children. Scientific Reports, 7 (1). doi: http:// doi.org/10.1038/s41598-017-12994-0

[17] LaPenta, D., Rubens, C., Chi, E., Cleary, P. P. (1994). Group A streptococci efficiently invade human respiratory epithelial cells. Proceedings of the National Academy of Sciences, 91 (25), 12115-12119. doi: http://doi.org/10.1073/pnas.91.25.12115

[18] Nozawa, T., Iibushi, J., Toh, H., Minowa-Nozawa, A., Murase, K., Aikawa, C., Nakagawa, I. (2021). Intracellular Group A Streptococcus Induces Golgi Fragmentation To Impair Host Defenses through Streptolysin O and NAD-Glycohydrolase. mBio, 12 (1). doi: http://doi.org/10.1128/mbio.01974-20 
[19] Soderholm, A. T., Barnett, T. C., Korn, O., Rivera-Hernandez, T., Seymour, L. M., Schulz, B. L. et. al. (2018). Group A Streptococcus M1T1 Intracellular Infection of Primary Tonsil Epithelial Cells Dampens Levels of Secreted IL-8 Through the Action of SpyCEP. Frontiers in Cellular and Infection Microbiology, 8. doi: http://doi.org/10.3389/fcimb.2018.00160

[20] Núñez-Acurio, D., Bravo, D., Aguayo, F. (2020). Epstein-Barr Virus—Oral Bacterial Link in the Development of Oral Squamous Cell Carcinoma. Pathogens, 9 (12), 1059. doi: http://doi.org/10.3390/pathogens9121059

[21] Silvoniemi, A., Mikola, E., Ivaska, L., Jeskanen, M., Löyttyniemi, E., Puhakka, T. et. al. (2020). Intratonsillar detection of 27 distinct viruses: A cross-sectional study. Journal of Medical Virology, 92 (12), 3830-3838. doi: http://doi.org/10.1002/ jmv. 26245

[22] Faden, H., Callanan, V., Pizzuto, M., Nagy, M., Wilby, M., Lamson, D. et. al. (2016). The ubiquity of asymptomatic respiratory viral infections in the tonsils and adenoids of children and their impact on airway obstruction. International Journal of Pediatric Otorhinolaryngology, 90, 128-132. doi: http://doi.org/10.1016/j.ijporl.2016.09.006

[23] Klymenko, Kh. (2021). Clinical features of infectious mononucleosis in children considering the aspects of the oral microflora colonization. The Scientific Heritage, 60 (2), 29-33. doi: http://doi.org/10.24412/9215-0365-2021-60-2-29-33

[24] Bin Abu Bakar, M., McKimm, J., Haque, S. Z., Majumder, A. A., Haque, M. (2018). Chronic tonsillitis and biofilms: a brief overview of treatment modalities. Journal of Inflammation Research, 11, 329-337. doi: http://doi.org/10.2147/jir.s162486

How to cite: Nadraga, A., Lutsyk, A., Klymenko, K., Khomyn, O. (2021). The investigation of bacterial adhesion of palatine tonsils epithelial cells in patient with infectious mononucleosis. EUREKA: Health Sciences, 3, 45-52. doi: http://doi.org/10.21303/ 2504-5679.2021.001835 